\title{
CONCHAS DE OSTRAS E CASCAS DE OVOS MOÍDAS COMO CORRETIVOS DA ACIDEZ DO SOLO
}

\author{
Paola Alfonsa Vieira Lo Monaco ${ }^{1}$, Gevson Roldi Júnior², Gustavo Haddad Souza Vieira ${ }^{3}$, Caroline Merlo \\ Meneghelli ${ }^{4}$, Carla da Penha Simon ${ }^{5}$
}

\begin{abstract}
RESUMO
Pesquisas têm sido realizadas com alguns resíduos sólidos que apresentam capacidade de correção da acidez do solo, como materiais alternativos ao calcário, em razão da elevada quantidade em que são descartados no ambiente. Objetivou-se, com a realização deste trabalho, avaliar a potencialidade de cascas de ovos e conchas de ostras moídas como corretivos da acidez do solo e obter a curva de neutralização da acidez de amostras de solo do horizonte B de um Latossolo Vermelho Amarelo (LVA). Avaliaram-se a capacidade dos resíduos como corretivos da acidez de acordo com a legislação vigente. Para a obtenção da curva de neutralização da acidez, os resíduos foram misturados em amostras de 500g de solo, nas doses de 0, 2, 4, 8, 16, 32, 64 e $128 \mathrm{t} \mathrm{ha}^{-1}$ e de 0, 2, 4, 8, 16 e $32 \mathrm{t} \mathrm{ha}^{-1}$ para as conchas de ostras e cascas de ovos, respectivamente. A mistura de solo e resíduo permaneceu incubada por um período de duas semanas, medindo-se, ao final desse período, o pH do solo na sua suspensão com água. Os dados obtidos foram submetidos à análise de regressão, ajustando-se a equação de estimativa do valor de pHem função da dose de resíduos aplicada. Os resíduos avaliados possuem elevado potencial como corretivos da acidez do solo e as doses necessárias para que o $\mathrm{pH}$ do horizonte B do LVA alcance o valor de 6,0 são de 5,25 e 5,20 t ha-1 , para as conchas de ostra e cascas de ovos, respectivamente.
\end{abstract}

Palavras-chave: Aproveitamento de resíduos.Correção da acidez.Disponibilidade de Cálcio

\section{ABSTRACT \\ OYSTERS AND EGG SHELLS GROUND FOR CORRECTION OF SOIL ACIDITY}

Research has been conducted with the alternative waste limestone, due to the high availability that are discarded and the opportunity to correct soil acidity. The objective of this work to evaluate the potential of egg shells and ground oyster shells as corrective of soil acidity and get the $\mathrm{B}$ horizon $\mathrm{pH}$ neutralization curve of a Yellow Red Latosol (LVA) using these the wastes. They evaluated the ability of the wastes as corrective of acidity according to the law. To obtain neutralization curve, the residues were mixed in samples of $500 \mathrm{~g}$ of soil, at the doses of $0,2,4,8,16,32,64$ and $128 \mathrm{tha}^{-1}$ and $0,2,4,8,16$ and $32 \mathrm{t} \mathrm{ha}^{-1}$, for oyster shells and egg shells, respectively. The mixture of soil and residues remained incubated for a period of two weeks, measuring at the end of this period, the $\mathrm{pH}$ in water. The data were submitted to regression analysis, adjusting the equation for estimating the $\mathrm{pH}$ value depending on the applied wastes doses. The assessed waste have high potential as soil acidity corrective and the necessary doses for the $\mathrm{B}$ horizon $\mathrm{pH}$ of LVA reach the value of 6.0 are 5.25 and $5.20 \mathrm{tha}^{-1}$, for shells oyster and egg shells, respectively.

Keywords: Wastes recovery. Acidity correction. Calcium availability.

Recebido para publicação em 31/08/2015. Aprovado em 01/12/2015.

1 - Engenheira Agrícola, Prof a do IFES, campus Santa Teresa-ES. E-mail: paolalm@ifes.edu.br.

2 - Estudante de Agronomia, IFES, campus Santa Teresa-ES. E-mail: junior_roldi@hotmail.com.

3 - Engenheiro Agrônomo, Prof. do IFES, campus Santa Teresa-ES. E-mail: ghsv@,ifes.edu.br.

4 - Estudante de Agronomia, IFES, campus Santa Teresa-ES. E-mail: carol.merlo@hotmail.com.

5 - Estudante de Agronomia, IFES, campus Santa Teresa-ES. E-mail: carlasimon2009@hotmail.com.

584 REVENG

584-590p.

ENGENHARIA NA AgRicultura, VIÇOSA - MG, V.23 N.6, NOVEMBRO / DEZEMBRO 2015 


\section{INTRODUÇÃO}

A maioria dos solos brasileiros apresentam limitações ao estabelecimento e desenvolvimento de grande parte das culturas, em decorrência de sua acidez e consequentes efeitos negativos nas plantas. De acordo com Sousa et al. (2007), a acidez do solo geralmente está associada à presença de Al e Mn trocáveis em concentrações tóxicas e de baixos teores de cátions de caráter básico, como o $\mathrm{Ca}$ e Mg. Quando em excesso, teores de $\mathrm{Al}$ e Mn representam um fator limitante ao crescimento das plantas. Para atenuar ou eliminar esses efeitos negativos, realiza-se a calagem, a qual tem por objetivo a neutralização dessa acidez, diminuindo ou anulando os efeitos tóxicos do $\mathrm{Al}$ e Mn, além de fornecer os nutrientes $\mathrm{Ca}$ e $\mathrm{Mg}$ para as plantas.

Como a aquisição de insumos agrícolas como calcários e fertilizantes vem se tornando cada vez mais dispendiosa para o produtor rural, Costa et al. (2013) ressaltam que o uso de fontes alternativas de resíduos industriais ou agroindustriais pode ser uma solução para tornar ambas as atividades mais sustentáveis e ecologicamente corretas. Com isso, visa-se a eliminação de um problema ambiental da indústria e, ao mesmo tempo, promove-se a redução nos custos de produção da agropecuária, beneficiando toda a cadeia, do produtor ao consumidor. Além disso, o uso de resíduos alternativos ao calcário pode diminuir o impacto sobre as reservas naturais dessa rocha, uma fonte natural não renovável.

Pesquisas têm sido realizadas com resíduos sólidos, materiais alternativos ao calcário, em razão da elevada quantidade em que são descartados no meio ambiente e a possibilidade de corrigirem a acidez do solo, tais como os resíduos gerados no beneficiamento de rochas ornamentais (FERRES et al., 2011;RAYMUNDO et al., 2013), escória de siderurgia (CHAVES; FARIA, 2008), farelo de concha de vôngole (LO MONACO et al., 2012), lodo de esgoto caleado (FIA et al., 2005; MATOS; MATOS, 2012), cinza de casca de arroz (ISLABÃO et al., 2014), resíduos de construção e demolição reciclados (LASSO et al., 2013), dentre outros.

Outros resíduos cujos usos podem ser voltados para a correção da acidez do solo são a casca de ovo e o farelo de conchas de ostras, já que, de acordo com Naves et al. (2007) e Lee et al. (2008), possuem carbonato de cálcio como principal constituinte em sua composição.

Depois de retirada a parte carnosa do molusco, suas conchas são descartadas no ambiente, geralmente de maneira inadequada. De acordo com Lo Monaco et al. (2012), quando dispostas em terrenos baldios e em áreas onde há seu acúmulo, causam mau cheiro, podendo ser um possível vetor de doenças, devido à atração de insetos e outros organismos, além de desconforto aos banhistas e prejuízos à paisagem. No caso da casca de ovo, sabe-se da grande quantidade com que é gerada em indústrias alimentícias, residências, padarias e restaurantes e, na maioria das vezes, desperdiçadas, em detrimento de usos mais nobres.

Aproveitar os resíduos de conchas e cascas de ovos na agricultura pode ser uma alternativa viável, principalmente se houver áreas agricultáveis próximas às áreas de descarte. Dessa forma, objetivou-se avaliar a capacidade das cascas de ovos e das conchas de ostras moídas como corretivos da acidez do solo e obter a curva de neutralização da acidez em amostras de solo do horizonte B de um Latossolo Vermelho Amarelo.

\section{MATERIAL E MÉTODOS}

A incubação das amostras de solo com os resíduos foram conduzidas no Laboratório de Solos do Instituto Federal de Educação, Ciência e Tecnologia do Espírito Santo, IFES - campus Santa Teresa, durante o mês de outubro de 2014.

O solo utilizado para incubação dos resíduos foi de um horizonte B de um Latossolo Vermelho Amarelo (LVA), textura argilosa (EMBRAPA, 1999), coletado na cidade de Santa Teresa - ES, cuja caracterização química pode ser visualizada no Quadro 1.

Quadro 1. Caracterização química do LVA utilizado na incubação das amostras.

\begin{tabular}{ccccccccccccc}
\hline $\begin{array}{c}\mathrm{pH} \text { em } \\
\text { água }\end{array}$ & $\begin{array}{c}\mathrm{MO} \\
\mathrm{g} \mathrm{dm}^{-3}\end{array}$ & $\begin{array}{c}\mathrm{P}^{1} \\
-\mathrm{mg} \mathrm{dm}^{-3}-\end{array}$ & $\begin{array}{c}\mathrm{K}^{1} \\
\mathrm{Ca}^{2}\end{array}$ & $\mathrm{Mg}^{2}$ & $\mathrm{Al}^{2}$ & $\mathrm{H}+\mathrm{Al}$ & $\mathrm{SB}$ & $\mathrm{T}$ & $\mathrm{t}$ & $\mathrm{m}$ & $\mathrm{V}$ \\
\hline 5,4 & 2,1 & 8,0 & 82,0 & 7,0 & 9,4 & 0,0 & 16,8 & 18,5 & 35,3 & 18,5 & 0,0 & 52,4 \\
\hline
\end{tabular}

${ }^{1}$ Extrator Mehlich; ${ }^{2}$ Extrator $\mathrm{KCl}$ a $1 \mathrm{M}$. 
As conchas de ostra utilizadas neste trabalho foram da espécie Crassostrea gigas, coletadas em restaurantes da região da Grande Vitória, ES. Já as cascas de ovos foram coletadas em restaurantes e domicílios do Município de Santa Teresa, ES. Ambos resíduos foram secos ao ar encaminhados ao referido laboratório, onde foram moídos em almofariz, para obter um pó fino (passado em peneira de malha 0,30 $\mathrm{mm}$ ). Em seguida, foram secos em estufa a $65^{\circ} \mathrm{C}$, por 48 horas.

Amostras do material moído e seco foram encaminhadas para o Laboratório de Análise de Solo, Tecido Vegetal e Fertilizante do Departamento de Solos da Universidade Federal de Viçosa, onde foram quantificados os teores de $\mathrm{Ca}, \mathrm{Mg}, \mathrm{CaO}$ e $\mathrm{MgO}$, por espectrometria,de acordo com o método descrito na Instrução Normativa $\mathrm{n}^{\circ} 28$ do MAPA (BRASIL, 2007).

Nas análises de eficiência relativa (ER) e o Poder de Neutralização (PN) foram utilizadas metodologias descritas por Matos (2015).

De posse da eficiência relativa e do poder neutralizante, foi possível calcular o Poder Relativo de Neutralização Total (PRNT), de acordo com a Equação 1.

$$
\text { PRNT }(\%)=\mathrm{PN} \times \mathrm{ER} / 100
$$

Para avaliar a capacidade dos resíduosno tocante às especificações e garantias mínimas exigidas para uso como corretivos da acidez, comparou-se os resultados obtidos nas amostras analisadas com o que está estabelecido na Instrução Normativa ${ }^{\circ}$ 35 do MAPA (BRASIL, 2006).

Para a obtenção da curva de neutralização, o pH do solo foi medido utilizando-se um peagâmetro de bancada, tendo sido obtido o valor de 5,4 (Quadro 1). Posteriormente, o pó da casca de ovo e das conchas de ostras foram misturados em amostras de $500 \mathrm{~g}$ do referido solo (terra fina seca ao ar), nas doses de 0,2 , $4,8,16,32,64$ e 128 tha $^{-1}$, de pó de concha de ostras, e doses de $0,2,4,8,16$ e $32 \mathrm{t} \mathrm{ha}^{-1}$, de pó de cascas de ovos. Em ambos os casos, o estudo foi realizado de forma independente.

As misturas de solo e pó de conchas e solo e cascas de ovos permaneceram sob condições de conteúdo de água equivalentes aos da capacidade de campo, em incubação por um período de duas semanas, tempo requerido para que ocorresse a reação do solo com o corretivo de acidez e fosse alcançado o equilíbrio. Esse período foi baseado na Resolução CONAMA 375 (Brasil, 2006), no tocante à determinação da elevação do $\mathrm{pH}$ do solo provocada por lodos de esgoto ou produto derivado tratados com cal, e por Matos (2015). Segundo a Resolução e o referido autor, o tempo de edição do $\mathrm{pH}$ no solo incubado é de 7, 14, 21 e 30 dias, entretanto se houver constância antes, as medidas podem ser encerradas. Como a reatividade com o solo é rápida e ocorre a referida constância após 14 dias, optou-se por utilizar esse período de tempo para incubação das amostras. Ao final, o material do solo foi secado ao ar e passado em peneira de $2 \mathrm{~mm}$ para medição do $\mathrm{pH}$ em água, suspensão preparada numa proporção de 1:2,5 (solo:água), utilizando-se, para isso, um peagâmetro de bancada.Todas as análises foram feitas com 3 (três) repetições.

Os dados obtidos foram submetidos à análise de regressão, a fim de se ajustar a equação de estimativa do valor de $\mathrm{pH}$ como função das doses aplicadas de pó de conchas de ostra e de cascas de ovos. As equações foram obtidas e os gráficos da curva de incubação foram gerados utilizando-se o programa SIGMA PLOT 9.0, escolhendo-se modelos matemáticos que apresentassem maior coeficiente de determinação, na significância dos coeficientes de regressãoe no fenômeno em estudo.

\section{RESULTADOS E DISCUSSÃO}

No Quadro 2 estão apresentados os resultados obtidos nas análises efetuadas para a avaliação da

Quadro 2. Composição química e caracterização dos resíduos no que se refere à capacidade de correção de acidez do solo

\begin{tabular}{lccccccc}
\hline \multirow{1}{*}{ Amostras } & Ca & CaO & Mg & MgO & PN* & ER & PRNT \\
& - & - & - & & & \\
& 31,9 & 44,6 & 0,5 & 0,8 & 86,5 & 100 & 86,5 \\
Cascas de ovos & 37,6 & 52,6 & 0,5 & 0,8 & 95,5 & 100 & 95,5 \\
Conchas de ostras & &
\end{tabular}

* relativo ao $\mathrm{CaCO}_{3}$.

Em que:PN - Poder de Neutralização; ER - Eficiência Relativa; PRNT - Poder Relativo de Neutralização Total 
capacidade dos resíduos em corrigir a acidez do solo.

De acordo com Souza et al. (2007), a acidez de um solo pode ser neutralizada utilizando vários compostos que podem liberar $\mathrm{OH}^{-} \mathrm{e}, \mathrm{ou}, \mathrm{HCO}_{3}$. A eficiência de um corretivo depende do teor de substâncias capazes de liberar $\mathrm{OH}^{-}$ou $\mathrm{HCO}_{3}^{-}$ (neutralizantes), tamanho das partículas (grau de moagem), estrutura cristalina do material e teor de Magnésio. A qualidade dos corretivos varia com a granulometria e com o Poder de Neutralização (PN) do material.

De acordo com dados apresentados no Quadro 2 , pode-se verificar que tanto o pó de cascas de ovos como o de conchas são muito ricos em cálcio e apresentam elevado poder de neutralização, o que lhes confere alto PRNT, caracterizando-os como resíduos de boa qualidade como corretivos de acidez do solo.

Segundo a Instrução Normativa ${ }^{\circ} 35$ do MAPA (BRASIL, 2006), na qual estão estabelecidas as normas sobre especificações e garantias, tolerâncias, registro, embalagem e rotulagem dos corretivos de acidez, destacam-se as especificações e garantias mínimas quanto ao PN, soma de óxidos $(\% \mathrm{CaO}+\% \mathrm{MgO})$ e PRNT de diferentes materiais a serem utilizados na correção de acidez do solo. Para outros corretivos de acidez, ou seja, exceto o calcário agrícola, calcário calcinado agrícola, cal hidratada agrícola ou cal virgem agrícola, o PN mínimo deve ser de $67 \%$ de $\mathrm{CaCO}_{3}$, a soma de óxidos mínima deve ser de $38 \%$ e o PRNT deve ser no mínimo de $45 \%$. Verifica-se no Quadro 2 que tanto as cascas de ovos quanto as conchas de ostras moídas atendem a todas as especificações estabelecidas na referida Instrução Normativa.

De acordo com os resultados obtidos, observase que os materiais estudados apresentaram elevada eficiência relativa (ER), o que já era esperado, tendo em vista que todo material foi pulverizado até passar em peneira de malha 0,30 $\mathrm{mm}$. Esse procedimento favorece maior área de contato ou de reação do resíduo com o solo. De acordo com Mello Filho et al. (2010), o fator granulométrico acarreta um aumento significativo nos índices do poder de neutralização $(\mathrm{PN})$ pois com a diminuição do tamanho das partículas do material, a área superficial em contato com o solo aumenta, fazendo com que aumente a velocidade de reação do material, aumentando a capacidade de neutralização da acidez do solo devido à maior liberação das espécies neutralizantes $\left(\mathrm{CaCO}_{3}, \mathrm{CaO}\right.$, $\mathrm{Ca}(\mathrm{OH})_{2}$ etc.) presentes.

Segundo Souza et al. (2007), os calcários agrícolas são classificados, no que se refere ao PRNT, em faixa A, PRNT entre $45,0 \%$ a $60,0 \%$; faixa B, PRNT entre $60,1 \%$ a $75,0 \%$, faixa C,PRNT entre $75,1 \%$ a $90,0 \%$ e faixa $D$, PRNT superior a $90,0 \%$. Dessa forma, o PRNT do resíduo da concha de ostra situa-se na faixa D e o da casca de ovo situa-se na faixa $C$.

$\mathrm{O}$ valor do poder relativo de neutralização total (PRNT) do resíduo da concha de ostras obtido neste trabalho é praticamente idêntico ao obtido por Lo Monaco et al. (2012) que, ao determinarem o PRNT de conchas de vôngole (Anomalocardia brasiliana), obtiveram 95,4\%. O PRNT obtido neste trabalho tanto para as conchas de ostras quanto para as cascas de ovos $(86,5 \%)$ pode ser considerado alto quando comparado com os obtidos para outros resíduos, tais como os apresentados nos trabalhos de Sobral et al. (2011), que obtiveram um valor de $45 \%$ em escória de siderurgia, de Islabão et al. (2014), que obtiveram apenas 3\% em cinza de casca de arroz, de Lasso et al. (2013), que obtiveram $13,4 \%$ em resíduos de construção e demolição reciclados.

De acordo com Souza et al. (2007), um dos fatores limitantes do solo ácido pode ser também o seu baixo conteúdo de $\mathrm{Ca}$ e Mg. Assim, a aplicação de um calcário que contenha $\mathrm{Mg}$, aliada ao seu efeito neutralizante da acidez, terá a adição de quantidade adequada de $\mathrm{Mg}$, o que evidentemente não acontece quando se utiliza o calcário calcítico. Segundo os autores, a relação $\mathrm{Ca}: \mathrm{Mg}$ é outra característica importante do corretivo, sendo que a relação apropriada varia de acordo com o solo e com as culturas. Uma relação molar comumente recomendada é a de 3:1 ou 4:1. No que se refere aos teores de Mg, Souza et al. (2007) classificam os calcários em calcíticos, com menos de $5 \%$ de $\mathrm{MgO}$; em magnesianos, entre 5 e $12 \%$ de $\mathrm{MgO}$ e dolomíticos, com maior de $12 \%$ de $\mathrm{MgO}$. Neste trabalho, a relação foi de, aproximadamente, 64:1 para as cascas de ovos e de 75:1 para as conchas de ostras, o que torna recomendável a complementação 
da adubação com fertilizantes que contenham $\mathrm{Mg}$, como o sulfato ou carbonato de $\mathrm{Mg}$ e mesmo o óxido de $\mathrm{Mg}$, já que algumas vezes os calcários dolomítico e magnesiano chegam ao agricultor a preço duas ou mais vezes mais caros que o calcário calcítico.

A soma de óxidos de $\mathrm{Ca}$ e $\mathrm{Mg}$ obtida neste trabalho para as cascas de ovos $(45,4 \%)$ e para as conchas de ostras $(53,4 \%)$ foram superiores à obtida por Lasso et al. (2013), que que foi de 8,6\%, ao avaliarem os resíduos de construção e demolição reciclados como corretivo da acidez do solo e por Balbinot Júnior et al. (2014), que obtiveram soma de 24,3\%, em resíduo de reciclagem de papel. Analisando-se somente as conchas de ostras, observa-se que os resultados obtidos neste trabalho foram superiores aos alcançados por Raymundo et al. (2013), que obtiveram soma de óxidos de aproximadamente $50 \%$ e por Bertossi et al. (2011), que obtiveram soma de óxidos de $49,68 \%$, ambos avaliando resíduos provenientes do beneficiamento de rochas de mármore.

$\mathrm{Na}$ Figura 1 está apresentada a curva $\mathrm{pH}$ do solo incubado com conchas de ostras moídas como função da dose, obtida com os dados gerados no ensaio de incubação das amostras. Utilizandose a equação matemática ajustada, estimou-se a dose necessária para elevação do $\mathrm{pH}$ do solo a 6,0 , considerado limite superior para um solo agrícola. De acordo com Souza et al. (2008), considera-se que a faixa ideal de $\mathrm{pH}$ para a maioria das culturas esteja entre 5,50 e 6,30.

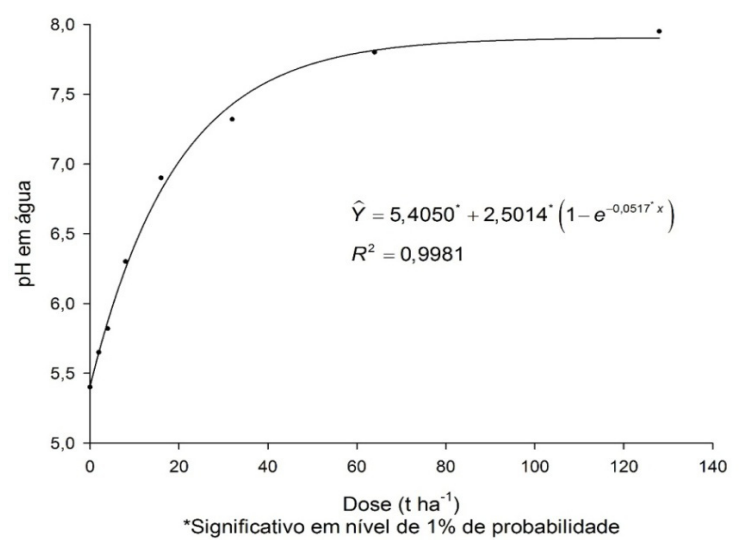

Figura 1. Valores de $\mathrm{pH}$ do solo coletado no horizontes $\mathrm{B}$ de um Latossolo Vermelho Amarelo em função da dose aplicada de pó de conchas de ostras.
Verifica-se, analisando-se a Figura 1, que o pó de conchas de ostras, mesmo quando adicionado nas menores doses, proporcionou aumento no $\mathrm{pH}$ do solo, em razão da reação alcalina deste material, o que é corroborado pelo relativamente alto $\mathrm{PN}$ $(95,5 \%)$.Estimou-se que uma dose de $5,25 \mathrm{t} \mathrm{ha}^{-1}$ seja suficiente para adequar o $\mathrm{pH}$ do solo analisado, ou seja aumento até pH 6,0.

$\mathrm{Na}$ Figura 2 está apresentada a curva de incubação do solo com o pó de cascas de ovos e sua respectiva equação, utilizada para estimativa da dose a ser aplicada do resíduo para aumento do seu $\mathrm{pH}$ até 6,0 .

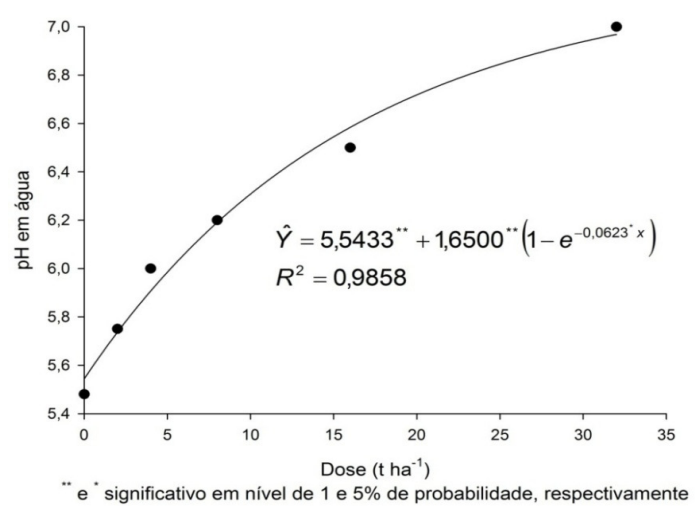

Figura 2. Valores de $\mathrm{pH}$ do solo coletado no horizontes B de um Latossolo Vermelho Amarelo distrófico em função da dose aplicada de pó de cascas de ovos.

Analisando a Figura 2, percebe-se que da mesma forma que o pó de conchas de ostras, o pó de cascas de ovos proporcionou aumento no $\mathrm{pH}$ do solo, devido a sua reação alcalina, o que é corroborado pelo seu relativamente alto PN $(86,5 \%)$.Considerando-se a correção do $\mathrm{pH}$ do solo até 6,0 , a aplicação de uma dose de $5,20 \mathrm{t} \mathrm{ha}^{-1} \mathrm{de}$ pó de cascas de ovos no horizonte $\mathrm{B}$ é suficiente para adequar o solo, no que se refere ao $\mathrm{pH}$, para o cultivo agrícola.

As doses de cascas de ovos e farelo de conchas estimadas nesse trabalho foram superiores às obtidas por Lo Monaco et al. (2012) que, utilizando pó de conchas de vôngole (Anomalocardia brasiliana) foram de 2,92 $\mathrm{t} \mathrm{ha}^{-1}$ e 3,35 $\mathrm{t} \mathrm{ha}^{-1}$, respectivamente, para a correção do $\mathrm{pH}$ (aumento até 6,5) de amostras de solo do horizonte A e B

\section{REVENG}


de um Latossolo Vermelho Amarelo distrófico. No entanto, foram bastante inferiores às doses recomendadas por Ferres et al. (2011), Lasso et al. (2013) e Matos e Matos (2012). Ferres et al. (2011), ao avaliarem a potencialidade do resíduo de beneficiamento do granito como corretivo da acidez do solo, obtendo a curva de neutralização da acidez, bem como as doses recomendadas deste resíduo, verificaram que, para correção do $\mathrm{pH}$ nos horizontes A e B de um Latossolo Vermelho Amarelo (LVA), seria necessária a aplicação de uma dose de 30,5 t ha-1 no horizonte A e de 96,7 t ha ${ }^{-1}$ no horizonte $\mathrm{B}$, para correção do $\mathrm{pH}$ até 6,5 . Lasso et al. (2013), ao avaliarem a utilização de resíduos de construção e demolição reciclados como corretivos de acidez de um Latossolo Vermelho Amarelo distrófico, verificaram a necessidade de aplicar doses superiores a $24 \mathrm{t}$ ha1, concluindo haver inviabilidade nessa aplicação, em razão do custo do frete do material.Matos e Matos (2012), ao avaliarem a utilização de lodo de esgoto caleado como corretivo da acidez em solos argilosos, concluíram que seriam necessárias doses de 12,64 a 19,27 t ha ${ }^{-1}$, para se atingir o $\mathrm{pH}$ de 6,5.

Os resultados obtidos são indicadores de que as conchas de ostras (Crassostrea gigas) e as cascas de ovos são resíduos sólidos promissores para utilização como corretivo da acidez de solos, principalmente pela menor quantidade a ser aplicada, para neutralização da acidez de um Latossolo Vermelho Amarelo.

\section{CONCLUSÕES}

- Os farelos de conchas de ostras e de cascas de ovos possuem elevado potencial como corretivo da acidez do solo e atendem a todas as especificações exigidas pela Instrução Normativa da Secretaria de Defesa da Agropecuária (SDA) do Ministério da Agricultura, Pecuária e Abastecimento (MAPA) 35/2006 para comercialização como tal;

- A dose de pó de conchas de ostras necessária para que o $\mathrm{pH}$ do horizonte B do LVA alcance o valor de 6,0 é de $5,25 \mathrm{t} \mathrm{ha}^{-1}$ e a de casca de ovos é de 5,20 tha-1.

\section{REFERÊNCIAS BIBLIOGRÁFICAS}

BALBINOT JÚNIOR, A.A.; VEIGA, M.; FONSECA, J.A.; VOGT, G.A.; ALBUQUERQUE, J. A.; COSTA, E. R. O. Aplicação de resíduo de reciclagem de papel em CambissoloHáplico e seu efeito no solo e no cultivo de plantas. Revista Brasileira de Ciência do Solo, v.38, n.1, p.336344, 2014.

BERTOSSI. A. P. A., CARDOSO. M. S. N., PRADO. A. C. A., POLIDORO. J.C., GARCIA. G.O., NEVES. M. A. Influência de resíduo de serragem de mármore na condutividade hidráulica do solo e na qualidade da água. Revista de Ciências Agrárias, p. 123 -134, 2011.

BRASIL. Ministério da Agricultura, Pecuária e Abastecimento. Instrução Normativa $\mathrm{n}^{\circ} 27$, de 05 de junho de 2006. Aprova os limites máximos de agentes fitotóxicos, patogênicos ao homem, animais e plantas, metais pesados tóxicos, pragas e ervas daninhas admitidos nos fertilizantes, corretivos, inoculantes e biofertilizantes destinados à agricultura. DOU, n.110, 9. jun. 2006.

BRASIL. Ministério da Agricultura, Pecuária e Abastecimento. Instrução Normativa $n^{\circ} 28$, de 27 de julho de 2007. Dispõe sobre manual de métodos analíticos oficiais para fertilizantes minerais, orgânicos, organominerais e corretivos. DOU, jul. 2007.

BRASIL. Ministério do Meio Ambiente. Resolução $n^{\circ} 375$, de 29 de agosto d 2006. Define critérios e procedimentos, para uso agrícola de lodos de esgotos gerados em estações de tratamento de esgoto sanitário e seus produtos derivados, e dá outras providências. DOU, ago. 2006.

CHAVES, L. G. G.; FARIAS, C. H. A. Escória de siderurgia e calcário na correção da acidez do solo e na disponibilidade de cálcio, magnésio e fósforo. Caatinga, v. 21, n. 5, p. 75-82, 2008.

COSTA, A.S. V.; HORN, A. H.; DONAGEMMA, G. K.; SILVA, M. B. Uso do resíduo de granito oriundo da serraria e polimento como corretivo e 
fertilizante de solos agrícolas. Revista Geonomos, v.18, n.1, p.23-27, 2013.

EMPRESA BRASILEIRA DE PESQUISA AGROPECUÁRIA - EMBRAPA. Centro Nacional de Pesquisa do Solo. Sistema Brasileiro de Classificação de Solos. Rio de Janeiro, 1999. 412p.

FERRES, G. C.; MATOS, A. T.; JÚNIOR, V. E.; BAPTESTINI, J. C. M.; LO MONACO, P. A. V.; RIBEIRO, I. C. A. Utilization of the ornamental rocks processing waste as soilacidity corrective. In: WASTES: Solutions, Treatments and Opportunities, 1, 2011, Guimarães - Portugal. Proceedings...Guimarães: International Conference, 2011. CD-ROM.

FIA, R.; MATOS, A. T.; AGUIRRE, C. I. Características químicas de solo adubado com doses crescentes de lodo de esgoto caleado. Engenharia na Agricultura, Viçosa, v.13, n.4, p.287-299, out/dez. 2005.

ISLABÃO, G. O.; VAHL, L. C.; TIMM, L. C.; PAUL, D. L.; KATH, A. H. Rice husk as corrective of soil acidity. Revista Brasileira de Ciência do Solo, v. 34, n. 1, p.934-941, 2014.

LASSO, P. R. O.; VAZ, C. M. P.; BERNARDI, A. C. C.; OlIVEIRA, C. R.; BACCHI, O. O. S. Avaliação do uso de resíduos de construção e demolição reciclados como corretivo da acidez do solo. Revista Brasileira de Ciência do Solo, v.37, n.6, p.1659-1668, 2013.

LEE, C. H.; LEE, D. K.; ALI, M. A.; KIM, P. J.Effects of oyster shell on soil chemical and biological properties and cabbage productivity as a liming materials. Waste Management, v.28, n.12, p.2702-2708, 2008.

LO MONACO, P.A.V.; MATOS, A. T.; EUSTÁQUI O JÚNIOR, V.; RIBEIRO, I. C. A.; TEIXEIRA, D. L. Utilização do farelo de conchas de vôngole na adsorção de fósforo e como corretivo da acidez do solo. Engenharia Agrícola, v.32, n.5, p.866-874, 2012.

MATOS, A.T. Manual de Análise de Resíduos
Sólidos e Águas Residuárias. Viçosa: UFV, 2015. 149p.

MATOS, M. P.; MATOS, A. T. Dose de cal hidratada e características químicas de um lodo de esgoto doméstico submetido à caleação. Engenharia na Agricultura, v.20, n.4, p.357-363, 2012.

MELLO FILHO, C. H. R.; OLIVEIRA, J. R.; ESPINOSA, D. C. R.; TENÓRIO, J. A. S. Caracterização e aplicação dos resíduos sólidos gerados na fabricação de precipitado de carbonato de cálcio como corretivo da acidez do solo. Revista Escola de Minas, v. 63, n.2, p. 271-272, 2010.

NAVES, M. M. V.; PRADO, C. M. M.; FERNANDES, D. C.; SERAFINI, A. B.Avaliação microbiológica do pó da casca de ovo e otimização da técnica de elaboração do produto. Pesquisa Agropecuária Tropical, Goiânia, v.37, n.2, p.113118, 2007.

RAYMUNDO, V.; NEVES, M. A.; CARDOSO, M. S. N.; BREGONCI, I. S.; LIMA, J. S. S.; FONSECA, A. B. Resíduos de secagem de mármores como corretivos da acidez do solo. Revista Brasileira de Engenharia Agrícola e Ambiental, v.17, n.1, p.4753, 2013.

SOBRAL. M. F.; NASCIMENTO, C. W. A.; CUNHA, K. P. V.; FERREIRA, H. A.; SILVA, A. J.; SILVA, F. B. V.Escória de siderurgia e seus efeitos nos teores de nutrientes e metais pesados em cana-deaçúcar. Revista Brasileira de Engenharia Agrícola e Ambiental, v.15, n.8, p.867-872, 2011.

SOUZA, D.M.G.; MIRANDA, L.N. \& OLIVEIRA, S.A.Acidez do solo e sua correção. In: NOVAIS, R. F.; ALVAREZ V.; V.H.; BARROS, N.F.; FONTES, R.L.F.; CANTARUTTI, R.B.; NEVES, J.C.L. (Ed.). Fertilidade do solo. Viçosa, MG: Sociedade Brasileira de Ciência do Solo, 2007. p. 205-274.

SOUZA, G. S.; LIMA, de J. S. S.; SILVA, S. A.; OLIVEIRA, R. B. Variabilidade espacial de atributos químicos em Argissolo sob pastagem. Acta Scientiarum. Agronomy, v. 30, n. 4, p. 589596, 2008. 